Abstract: Deeply influenced by the ideas of Paulo Freire, my research has focused on the transformative potential of CBAE practices. I have been intrigued about the potential for art education to embrace the artistic practices in one's local community as valid and important educational content.

During my visit to UFG last summer I had the opportunity to share with an interested audience that included FAV art education students, graduate students from the University of Cincinnati, and area teachers the importance of "making the familiar strange" or engaging in the interpretive process that allows for recognition of everyday culture and local art. My research and personal experiences indicate that such validation requires a distanciation that enables new interpretations about familiar objects and phenomena.

Key-words: local community; everyday culture and local art. 


\section{Celebrando autorias: arte, comunidade e cotidiano em arte-educação}

Flávia M. C.

BASTOS

Este texto apresenta um diálogo entre as minhas experiências em Arte-Educação Baseada na Comunidade ${ }^{l}$ nos Estados Unidos e a influência Paulo Freireina na minha abordagem educacional. Alargar os horizontes do que é comumente considerado arte tem várias implicações. Primeiramente há uma relativização do discurso dominante que leva à ampliação do que pode ser considerado arte. Através deste movimento, novas maneiras de se ver e pensar a arte podem ser descobertas. Esta concepção mais fluída possibilita aproximações entre arte e experiência cotidiana (Richter, 2003; Certeau, 1997), criando espaços de reflexão e investigação sobre o que constitui arte, suas diferentes formas e funções. Questionando os fundamentos de visões tradicionais, proponho valorizar as interpretações daqueles que experienciam arte. Não se trata de desbancar a arte consagrada, mas de repensá-la. Enquanto uma vertente importante da cultura ocidental, a arte consagrada sintetiza idéias, símbolos e conceitos fundantes à história desta civilização. No entanto, restringir arte à estas obras significa a exclusão de outras tradições importantes como as inspiradas pelo folclore ou cultura popular. Definições mais abrangentes de arte e cultura inspiram novas interpretações sobre a relação entre arte e cotidiano.

Palavras-chave: comunidade local, cultura do cotidiano e arte local. 
A arte se dirige à mente, não aos olhos.

Arte é linguagem, um instrumento de conhecimento, um instrumento de expressão. Jean Dubuffet ${ }^{2}$

Ao emitir a palavra artevalemo-nos de uma gama de conceitos. Quando nos apoiamos em óticas conservadoras e definições corriqueiras, falamos em uma arte de museus, de obras primas e molduras douradas. Esta é uma arte que se apresenta a nós pré-classificada, com a qual o nosso engajamento, frequentemente se limita à fruição, e a expectativa de uma experiência agradável. Arte, assim apriori definida, indexa o belo que é capaz de enobrecer e transcender nossa aborrecida existência cotidiana. Esta visão de arte não me intessa muito - não apela a minha curiosidade de sujeito, nem aos meus interesses de educadora. Esta visão de arte mantém e justifica o status quo e suas hierarquias. Aposto em uma visão de arte comprometida com uma ordem social mais igualitária, cujo estudo e conhecimento leve a uma maior conscientização.

Convido, portanto, a buscarmos uma definição mais subversiva de arte. Para tanto é imperativo re-ver conceitos tradionais de arte. Sugiro que não somente re-examinemos objetos convencionalmente considerados arte, mas que investiguemos os vários processos, idéias e instituições que validam sua existência. Muitas vezes é necessário, metafórico e literalmente, olhar atrás da tela. Lá descobrimos esboços e desenhos preliminares e evidências de projetos a serem realizados. É atrás da tela, no interior de uma escultura, ou no lado avesso de uma tapeçaria que desvelamos aspectos essenciais a estas obras suas estruturas, suas entranhas. Atrás da tela, qualquer obra de arte consagrada, por mais valiosa, se aproxima de outros trabalhos humanos. Aproximar arte e outro fazere humanos é a base de um conceito de arte que transgride as definições com que estamos acostumados.

Ao longo da história, diferentes definições de arte têm criado debates entre críticos e historiadores, geralmente levando a polarizações. Superar esta controvérsia é importante para aproximar a arte que se encontra nos dois lados da tela. De um lado, 
uma arte de imagens reconhecidas como tal; do outro, vários fazeres humanos não reconhecidos como arte. Proponho que superemos estas dicotomias antigas entre artesato e artes visuais, costura e escultura, paisagismo e jardinagem (MCFEE, 1991), em favor de um conceito mais robusto e trasformador. Esta visão integra processos criativos menos consagrados e relativiza paradigmas tradicionais. Neste artigo discuto duas expêriencias em arte-educação, uma nos Estados Unidos e uma no Brasil, que compartilham esta visão abrangente de arte. Central a esta visão é um alargamento do espectro do que é considerado arte para incluir por exemplo, a arte tradicionamente feita por mulheres, o artesanato regional, a arte de artistas sem formação acadêmica e de artistas locais (GUIMARÃES, 2001). Assim, ampliar a gama de possiveis autorias em arte renova a forma como esta é vista e estimula, em conseqüência, novas propostas para o seu ensino.

\section{Ampliando definiçõos: uma experiência nos Estados Unidos}

Usamos a palavra artista para descrever alguém que faz um quadro ou escultura, ou também aquele que maquia um rosto para um espetáculo, ou mesmo aquele que age de uma forma não convencional. Da mesma forma, a palavra artes é imbuída de valores distintos quando utilizada nas expressões artes plásticas ou artes culinárias. Claramente há uma distinção de valor entre estas formas, evidenciando as hierarquias que marcam nossa forma contemporânea de pensar, agir e falar sobre arte. Somente um peturbamento dessas noções convencionais (BASTOS, 2006) nos leva a questionar porquê algumas formas como a pintura e escultura são consagradas enquanto outras, como a cerâmica, carpintaria ou bordado, ocupam lugar secundário. Relato a sequir uma breve história que ilustra o impacto de conceitos limitados de arte. Estes conceitos tornaram a arte da comunidade de Orleans, no estado de Indiana, nos Estados Unidos, praticamente invisível para seus habitantes. Recordo vividamente meu entusiasmo durante o início do trabalho de campo para minha pesquisa de doutorado, a arte 
local pulsava para mim, colorindo, enfeitando e caracterizando a comunidade. No entanto, para os modores de Orleans, esta era praticamente ignorada.

Após as primeiras visitas à Orleans nas quais buscava entrevistar moradores e artistas da comunidade sobre a arte produzida ali, voltei para a universidade preocupada com o que então me parecia a inviabilidade de meu estudo. Eu sabia da existência de artistas naquela pequena comunidade rural do meio-oeste americano. Havia visto sua arte exibida em feiras na região, comentada em livros, exposta na biblioteca da cidade, discutida pela professora de arte da escola. No entanto, todas minhas tentativas de identificar artistas durante minhas primeiras vistas à cidade haviam fracassado. Perguntei a alunos, professores e administradores da escola, transeuntes, comerciantes, e políticos da comunidade, a senhores aposentados sentados nas mesas do Harley's (o café no centro da cidade que foi a mais antiga estação de ônibus do estado) se conheciam algum artista nas redondezas. Todos eles meditavam por um instante para dizer logo em seguida, "Não, eu não conheço nenhum".

Busquei a sabedoria de um dos membros de meu comitê de tese. Expús meu impasse e ouvi seu conselho. “Tu estás fazendo a pergunta errada" ele me disse. No começo não entendi. "Se eu quero encontrar artistas, devo pergutar onde eles estão", eu pensava. Mais tarde ficou claro que de fato o que eu e os moradores de Orleans consideravámos arte eram coisas diferentes. Passei então a perguntar quem eram as pessoas que faziam objectos com as próprias mãos. Assim, como que magicamente, um universo vibrante de fazeres artísticos descortinou-se. Eram pintores, escultores, artesãos de várias especialidades e estudiosos das tradições locais. Enfim, uma massa crítica de pessoas que integravam a arte a suas vidas.

Entendi que a excessiva familiaridade com estes artistas e suas obras ia de encontro à idéia de que arte se constitui em algo distante: objetos pertencentes a outras épocas e culturas, a outros lugares e estilos de vida. A possibilidade de existência de uma arte local entrava em conflito com a falta de formação acadêmica da maior parte dos artistas de Orleans, o fato dos artistas não sobrevivem de sua arte e de serem na mairoia mulheres 
(apesar dos poucos homens receberem maior destaque e reconhecimento). Elas (eles) evitam a denominação artista, dizendo sentir-se mais confortáveis com o título artesã (o).

Mais que uma questão de nomenclatura, artistas e pessoas da comunidade valiam-se de critérios que tornavam a arte produzida ali, na sua comunidade, praticamente invisível. Glassie (1989) discutiu e problematizou as noções e os preconceitos que fundamentam o discurso e a visão convencionais sobre arte. Identificando as limitações de conceitos que privilegiem somente certas formas e elaborando uma definição que desse conta da multitude de usos e formas que a arte assume em diversas culturas. Glassie define arte como o que é encontrado de melhor, mais profundo e mais rico em qualquer cultura. Definir arte como uma fecunda projeção da cultura, abre caminho para considerarmos um amplo leque de autorias. De acordo com Glassie, arte é fazer - o fazer de um quadro, de um móvel, de um objeto de barro, de uma tapeçaria. Nesta visão democrática, os fazeres humanos são proclamados como intrinsica e potencialmente artísticos.

Alargar os horizontes do que é comumente considerado arte tem várias implicações. Primeiramente há uma relativização do discurso dominante que leva à ampliação do que pode ser considerado arte. Através deste movimento, novas maneiras de se ver e pensar a arte podem ser descobertas. Esta concepção mais fluída possibilita aproximações entre arte e experiência cotidiana (RICHTER, 2003; CERTEAU, 1997), criando espaços de reflexão e investigação sobre o que constitui arte, suas diferentes formas e funções. Questionando os fundamentos de visões tradicionais, proponho valorizar as interpretações daqueles que experienciam arte. Não se trata de desbancar a arte consagrada, mas de repensá-la. Enquanto uma vertente importante da cultura ocidental, a arte consagrada sintetiza idéias, símbolos e conceitos fundantes à história desta civilização. No entanto, restringir arte à estas obras significa a exclusão de outras tradições importantes como as inspiradas pelo folclore ou cultura popular. Definições mais abrangentes de arte e cultura inspiram novas interpretações sobre a relação entre arte e cotidiano. Especificamente, aproximações entre a arte e fazeres cotidianos assumem 
significados muito especiais para práticas educativas que possuam um compromisso social.

\section{A comunidade como um espaco de arte-educação: uma experienciência em Goiás}

Recentemente, durante o mês de junho de 2005, ministrei um curso sobre as relações entre arte e comunidade para alunos do programa de Licenciatura em Artes Visuais da Universidade Federal de Goiás (UFG). Além de alunos do programa, também participaram do curso professores do sistema de ensino local e alunos de pós-graduação. O objetivo do curso era fomentar o interesse por uma linha de estudos e pesquisas sobre a relação entre arte e comunidade na UFG. Minha aula inaugural buscou promover um diálogo entre as minhas experiências em Arte-Educação Baseada na Comunidade ${ }^{3}$ nos Estados Unidos e a influência Paulo Freireina na minha abordagem educacional. Este curso e as atividades relacionadas a ele fazem parte de um acordo de relações internacionais firmado a UFG e a Universidade de Cincinnati, onde trabalho. Oriundo das similaridades existentes entre minha linha de pesquisa e a da professora Leda Guimarães, o convênio entre estas duas instituições de ensino superior tem por objetivo proporcionar o intercâmbio entre alunos e professores e também criar um espaço de discussão, situando a teoria e a prática da Arte-Educação Baseada na Comunidade num contexto internacional onde situações de perturbamento e as reflexões decorrentes destas se façam mais constatmente.

\section{Paulo Freire}

Freire enfatizou a posição do aprendente em relação ao mundo como propiciando as condições essenciais à interpretação. Assim é fundamental considerar o contexto que envolve o ato de aprender. Em um exemplo dos métodos usados por Freire, os participantes dos "círculos de cultura" eram convidados a examinar suas vilas e comunidades e a coletar os nomes das fer- 
ramentas, lugares e atividades importantes em suas vidas. Esta nova mirada sobre estes objetos e eventos familiares despertava o questionamento e o diálogo sobre sua situação de vida. A narrativa que segue descreve a experiência de um círculo de cultura em Monte Mário durante uma campanha de alfabetização em Santo Tomé e Prícipe na África nos anos 70. O impacto desta narrativa indica não só a importância de conhecermos nossas comunidades, mas também alude ao poder de certas representações visuais de despertarem reflexões críticas.

Visitamos o círculo de cultura na pequena comunidade pesqueira de Santo Mário. Eles tinham como palavra geradora o termo "bonito", o nome do peixe, e como codificação um desenho expressivo de sua vila, representando a vegetação local, casas típicas, barcos de pesca no mar e um pescador segurando um bonito. Os alunos se ficaram olhando para esta codificação em silêncio. De repente, quatro deles se levantaram de uma vez e como se eles tivessem combinado de antemão; caminharam até a parede onde a codificação ${ }^{5}$ estava pendurada. Eles a examinaram atenta e longamente. Depois eles foram ate a janela e olharam para fora. Olhando um para o outro como se estivessem surpresos e olhando novamente para a codificação eles disseram; "Isto é Monte Mário. Monte Mário é desse jeito e a gente não sabia”. (FREIRE, 1987, 67-8).

Através de uma representação visual, estas pessoas alcançaram um distanciamento de seu próprio mundo para somente então poder reconhecê-lo. Reconhecimento, entendido desta maneira, é um ato de conscientização pois oportuniza atribuir novos significados a um fenômeno familiar. Na verdade, nós não simplesmente vemos, nós vemos como, em relação, em termos, a respeito, à luz... Estes pescadores à luz da representação de sua vila reconheceram a si mesmos. Experiências de reconhecimento como esta sugerem que práticas de Arte-Educação Baseada na Comunidade tem o potencial de promover mudanças através do estudo crítico da arte local. O estudo da arte própria da cultura dos alunos como proposto pela Arte-Educação Baseada na Comunidade, favorece o desenvolvimento de habilidades para interpretar, questionar, e participar conscientemente na cultura e sociedade locais. Inpirada pela pedagogia de Paulo Freire, minha visão de Arte-Educação Baseada na Comunidade consiste em um projeto educacional cujo compromisso funda- 
mental é desenvolver a consciência crítica através do estudo da arte produzida localmente.

Uma das atividades que desenvolvi com os participantes do curso de Licenciatura em Artes Visuais na UFG combinou estas idéias de Paulo Freire com uma estratégia de planejamento urbano, chamada mapeamento dos bens e valores da comunidade (KRETZMANN \& MCKNIGHT, 1993). Convidei os participantes do curso a desenhar um mapa da sua comunidade e identificar (marcar, escrever, desenhar) nestes os bens e valores que eles conheciam na sua comunidade. Os mapas evidenciaram várias marcas e anotações, então convidei os alunos a relatá-las ao grande grupo. Assim, as narrativas individuais sobre segmentos da comunidade iam se somando e justapondo, criando um mosaico de conhecimentos sobre a comunidade.

De uma certa forma, o impacto deste exercício é semelhante a experiência de recomencimento descrita por Paulo Freire. Os alunos relataram seus mapas para os demais na sala de aula imediatamente iniciando um diálogo em que o seu conhecimento da comunidade era trocado e expandido. Eu propus ao grupo que descrevesse áreas vizinhas, ampliando assim a cobertura geográfica do nosso conhecimento. No entanto, o resultado mais importante deste exercício, identificado no entusiasmo palpável do grupo, foi o aprofundamento do conhecimento de algumas regiões da cidade. Eu testemunhei através das trocas que aconteceram como os alunos entenderam o potencial de considerar a comunidade como o foco de ações educativas em arte. Para este grupo, barreiras entre concepções eruditas de arte e experiência cotidiana na comunidade foram rompidas, ou pelo menos perturbadas a ponto de serem reorganizadas numa nova configuração. 


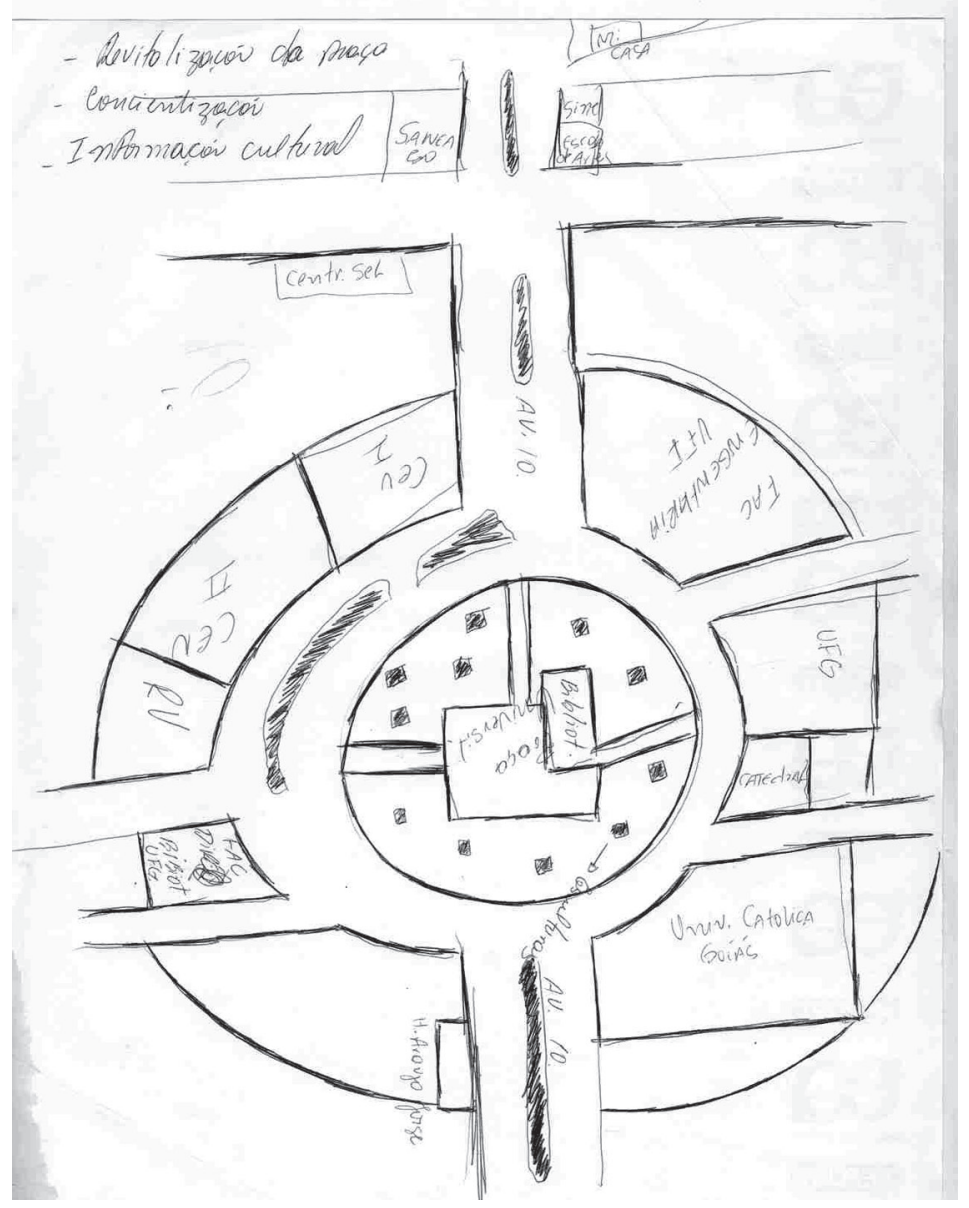

Mapa de Alunos da UFG 


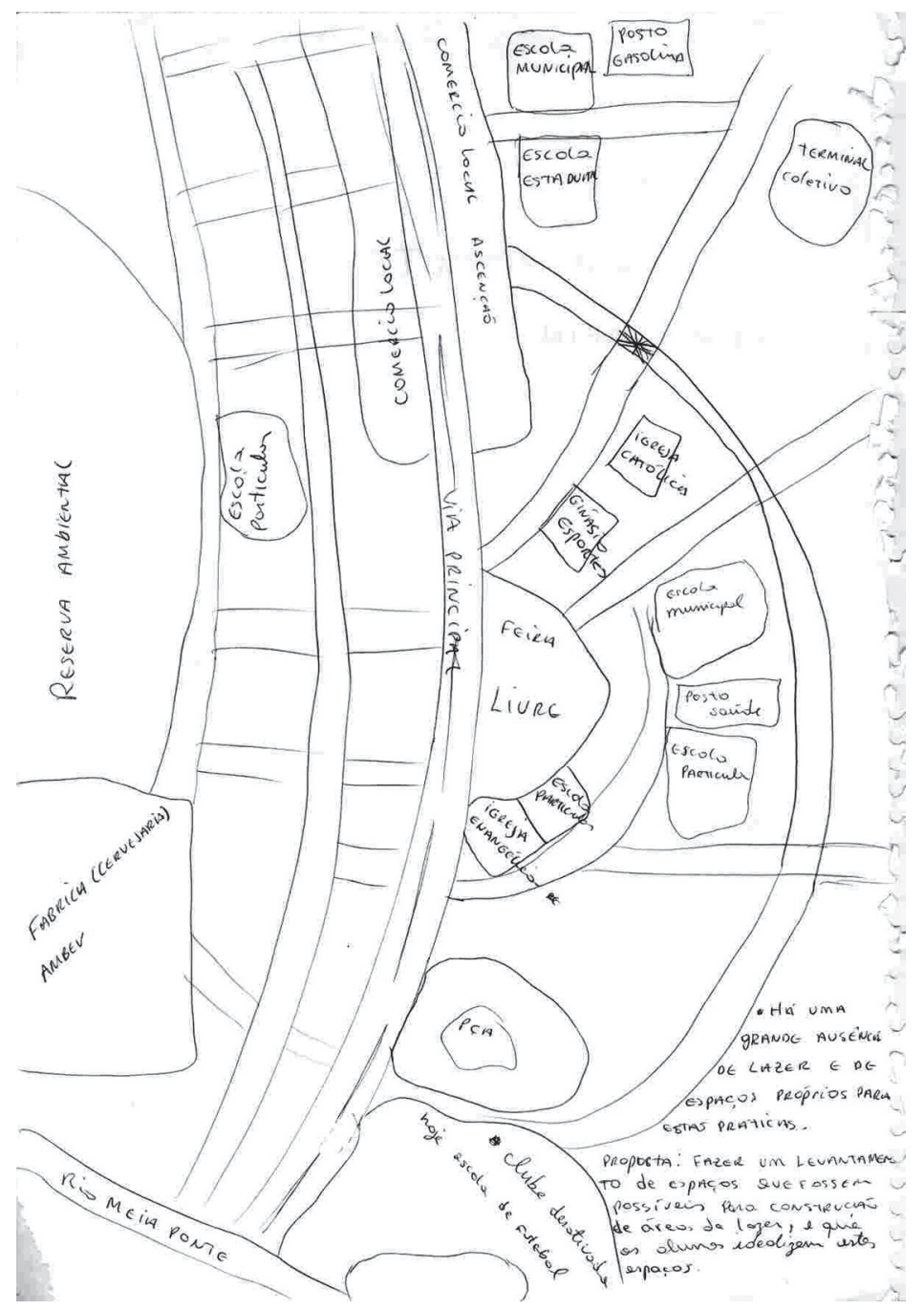

Mapa de Alunos da UFG 


\section{Buscando visões mais democráticas de arte}

Barreiras entre objetos destinados à apreciação e objetos utilitários, ou seja, arte e artesanato, pertencem e validam uma ordem social conservadora (TUCKER, 1996). Lippard (1996) comenta que, de modo semelhante, noções predominantes de bom gosto estão apoiadas numa específica visão de ordem social. Ou seja, discursos e práticas validam e hierarquizam diferentes formas de arte. Assim pintura, desenho e escultura são consideradas superiores à cerâmica, carpintaria ou alfaiataria. Esta divisão nos remete não apenas a categorias existentes dentro do mundo das artes, mas revela uma visão de saber e de sociedade que distingue, por exemplo, entre saber prático e científico, entre cultura erudita e popular e entre classes sociais. Distinções entre arte que se destina a apreciação e arte de caráter utilitária são impostas. Linhas horizontais bem definidas são traçadas por críticos, colecionadores, curadores e historiadores de arte entre diferentes tradições artísticas como arte sofisticada e artesanato, as quais impedem um debate mais amplo sobre o papel da arte em sociedade, bem como o interrelacionamento ente diferentes gêneros artísticos (TUCKER, 1996). De acordo com Hauser (1988), em cada momento considerado, existem pelo menos tantas tendências em arte quantos os estratos culturais, portanto a história da arte deveria ter em conta mais do que habitualmente, as exigências e os objetivos especiais de grupos que receberam educação e treinamento artístico diferente. Se assim fizesse, teria que se valer de amostragens para descrever o desenvolvimento da arte proporcionando o entendimento de que há sempre várias tradições diferentes seguindo paralelamente. Hauser considerou que a tarefa de incluir na narrativa histórica sobre arte em um determinado período amostras das diferentes tradições artísticas existentes como uma das mais simples. A dificuldade residiria em pesquisar, relacionar e discutir como a situação de classe e o nível de educação estão relacionados na produção destas diversas tradições artísticas.

Historicamente, no Brasil, a distinção entre tradições artísticas populares e acadêmicas iniciou com a criação da Escola Nacional de Belas Artes, em 1826, ainda na época de D. João VI. Organizada por um grupo de artistas neoclássicos ${ }^{6}$ franceses a 
criação de uma escola de ensino superior de artes transformou fazeres e atividades essencialmente populares como escultura e arquitetura em atividades de uma elite educada de acordo com padrões europeus. A tradição brasileira era marcadamente barroco-rococó ${ }^{7}$. As incursões da arte brasileira no neoclássico haviam sido esporádicas. Segundo Barbosa (1992):

Afastando-se a arte do contato popular, reservando-a para de happy few e os talentosos, concoria-se, assim, para alimentar um dos preconceitos contra a arte até acentuada em nossa sociedade, a idéia de arte como atividade supérflua, um babado, um acessório da cultura. (p.20)

De acordo com Dewey (1980), a separação entre arte e os processos mais corriqueiros da vida cotidiana é um comentário trágico, mesmo patético sobre a vida contemporânea. As rígidas hierarquias que classificam a arte circunscrevem e limitam nossas experiências. A ruptura de dicotomias entre arte e artesanato, arte aplicada e pura, arte acadêmica e popular não é apenas questão de nomenclatura. Transformada em ação, esta nova ordem promete materializar um conceito de arte que celebra a ampla gama de autorias humanas a projetos educacionais democráticos. Noções participatórias de sociedade entrelaçam a arte e a vida cotidiana e sugerem novas abordagens em arte educação. Nossas artes, ou linguagens de criação e expressão podem abranger da jardinagem ao tricô, da escultura à culinária, da pintura à decoração. O desafio que se coloca claramente para a arte-educação é o de elaborar e implementar propostas que deêm conta destas idéias mais amplas e democráticas sobre arte, e principalmente transformem o ensino de e sobre arte numa parte integral das aprendizagens escolares.

\section{Celebrando autorias}

Arte é linguagem. Como propôs Dubuffet, arte se dirige à mente, fala à inteligência, comunicando saberes pertinentes a um tempo, espaço, grupo social. Arte é, portanto pensamento e conhecimento. Entendida de uma forma ampla, arte pode ser definida como um fazer tipicamente humano, involvendo criar 
objetos de funções utilitárias e estéticas, organizar eventos de dimensões sociais, simbólicas e místicas. A arte nos situa no mundo da cultura enquanto sujeitos, abrindo possibilidades de interpretação e de autoria. Atividades de arte-educação organizadas a partir destas idéias buscam estabelecer relações entre a arte consagrada e arte produzida na comunidade, investigando as linguagens criadoras dos alunos, suas famílias e da comunidade local. Arte em um projeto de ensino democrático busca criar um espaço de reflexão sobre as nossas várias tradições artísticas, as condições históricas que levam a sua valorização, e fundamentalmente promover um enagajamento com a comunidade. Há várias formas de deselvolver projetos de Arte-Educação Baseada na Comunidade. Meu comprometimento está ligado àqueles que tem o potencial de promover mudanças sociais através de um entendimento amplo de arte e o consequente empoderamento dos participantes. Conectar arte e comunidade no cotidiano da arte-educação abre portas para uma forma politizada de ensinar, aprender e agir nas comunidades com as quais interagimos. $\mathrm{O}$ convite está posto.

\section{Notas}

1- O termo Arte-Educação Baseada na Comunidade é a tradução de Community-Based Art Education que designa praticas educacionais que derivam da comunidade.

2- O artista Jean Dubuffet criou o termo art brut para designar a arte criada por doentes mentais, artistas populares, bem como as formas de arte que não seguissem os padrões acadêmicos (CHILVERS, 1996).

3- O termo Arte-Educação Baseada na Comunidade é a tradução de Community-Based Art Education que designa praticas educacionais que derivam da comunidade.

4- Círculos de cultura são os grupos de adultos que estão se alfabetizando. Essencial na metodologia Freiriana, a roda marca o relacionamentos horizontal entre professor e aluno.

5- Codificações são parte da metodologia de Paulo Freire e consistem de uma representação visual da situação de vida dos alunos. São objetos de conhecimento, mediando os sujeitos e o ato de aprender.

6- Neoclassicismo foi o movimento predominante na arte e na arquitetura européia do final do século XVII e início do século XIX, caracterizado pelo desejo de recriar o espírito heróico, bem como os padrões decorativos, da arte da Grécia e de Roma (CHILVERS, 1996).

7- Barroco designa o estilo dominante da arte européia no do período compreeendido entre o maneirismo e o rococó no século XVII. Sua ênfase coloca-se no equilíbrio, através da harmonia das partes (CHILVERS, 1996). 


\section{Referências Bibliográficas}

BARBOSA, A. M. Arte-educação no Brasil. São Paulo: Perspectiva, 1992.

BASTOS, F.M. C. O perturbamento do familiar: Uma Proposta Teórica para a Arte-Educação Baseada na Comunidade. Em A.M. Barborsa (org.). O ensino contemporâneo de arte: Consonâncias internacionais. São Paulo: Cortez. (impressão, previsto para março de 2006).

BASTOS, F. M. C. Making the familiar strange: Teachers' interpretations of community art. Tese de Doutorado, Indiana University, 1999.

CERTEAU, M. The practice of everyday life. Berkely: University of California Press, 1988.

CHILVERS, I. (Ed.). Dicionário Oxford de arte. São Paulo: Martins Fontes, 1996.

DEWEY, J. Art as experience. New York: Perigee, 1980.

FREIRE, P. Literacy: Reading the word and the world. South Hadley, MA: Bergin Gravey. 1987.

GLASSIE, H. The spirit of folk art. New York: Harry Abrams, 1989.

GUIMARÃES, L. (Org.). Objetos populares da cidade de Goiás. Goiânia: UFG-SEBRAE, 2001.

HAUSER, A. Teorias da arte. Liboa: Presença, 1988.

KRETZMANN, John \& MCKNIGHT, John. Building Communities from the Inside Out: A Path Toward Finding and Mobilizing a Community's Assets. Chicago, IL: ACTA Publications, 1993.

LIPPARD, L R. Mixed blessings: New art in a multicultural America. New York, 1996.

MCFEE, J. K. Art education progress: A field of dichotomies or a network of mutual support. Studies in Art Education, 32 (2), 70-82, 1991.

RICHTER, Y. M. Interculturalidade e estética do cotidiano no ensino das artes visuais. Campinas: Mercado das Letras, 2003.

TUCKER, M. A labor of love. New York: The New Museum of Contemporary Art, 1996. 


\section{Flávia Maria Cunha Bastos}

Professora do Departamento de Arte Educação da University of Cincinnati. Dirige o programa de Mestrado em Arte Educação e o Projeto Art in the Market. Suas mais recentes publicações incluem o artigo, The Art in the Market Project: Addressing Racial Issues through Community Art (Spring, 2004) Journal of Cultural Research in Art Education, Vol. 22. e o capítulo traduzido aqui, Making the Familiar Strange: A community-based Art Education Framework do livro Contemporary Issues in Art Education (2002). Flávia Bastos fez várias palestras e apresentações em conferências e congressos no Brasil, Estados Unidos, e Espanha. Em 2001 ela ministrou um curso sobre avaliação no NACE. 